\title{
Evaluation of in vitro antimicrobial susceptibility of Bacillus anthracis strains isolated during anthrax outbreaks in Italy from 1984 to 2017
}

\author{
Viviana Manzulli ${ }^{1, *}$, Antonio Fasanella ${ }^{1}$, Antonio Parisi ${ }^{1}$, Luigina Serrecchia ${ }^{1}$, Adelia Donatiello ${ }^{1}$, Valeria Rondinone ${ }^{1}$, \\ Marta Caruso $^{1}$, Sabine Zange ${ }^{2}$, Alina Tscherne ${ }^{2}$, Nicola Decaro ${ }^{3}$, Carmine Pedarra ${ }^{1}$, Domenico Galante ${ }^{1}$ \\ ${ }^{I}$ Anthrax Reference Institute of Italy, Experimental Zooprophylactic Institute of Puglia and Basilicata Regions, Foggia 71121, Italy \\ ${ }^{2}$ Bundeswehr Institute of Microbiology, Munich 80937, Germany \\ ${ }^{3}$ Department of Veterinary Medicine, University of Bari, Valenzano 70010, Italy
}

\begin{abstract}
Anthrax, caused by Bacillus anthracis, is a non-contagious infectious disease that affects a wide range of animal species (primarily ruminants) including humans. Due to the often-fatal outcome in humans, quick administration of definitely effective antimicrobials is crucial either as prophylaxis or as a clinical case therapy. In this study, 110 B. anthracis strains, temporally, geographically, and genetically different, isolated during anthrax outbreaks in Italy from 1984 to 2017, were screened using a broth microdilution method to determine their susceptibility to 16 clinically relevant antimicrobial agents. The strains were isolated from various matrices (human, animal, and environmental samples) and were representative of thirty distinct genotypes previously identified by 15 -loci multiple-locus variable-number of tandem repeats analysis. The antimicrobials tested were gentamicin, ceftriaxone, streptomycin, penicillin G, clindamycin, chloramphenicol, vancomycin, linezolid, cefotaxime, tetracycline, erythromycin, rifampin, amoxicillin, ciprofloxacin, doxycycline, and trimethoprim. All isolates were susceptible to most of the tested antimicrobials, with the exception of trimethoprim for which all of them showed high minimal inhibitory concentration values. An intermediate level of susceptibility was recorded for ceftriaxone and cefotaxime. Although the Centers for Disease Control and Prevention recommend the use of doxycycline, ciprofloxacin, penicillin $\mathrm{G}$, and amoxicillin for treatment of human cases and for post-exposure prophylaxis to anthrax spores, this study shows a high degree of in vitro susceptibility of B. anthracis to many other antimicrobials, suggesting the possibility of an alternative choice for prophylaxis and therapy.
\end{abstract}

Keywords: Bacillus anthracis; Antimicrobial susceptibility testing; Anthrax treatment; Minimum inhibitory concentration

\section{Introduction}

Anthrax is a serious infectious disease, that mainly affects ruminants (farmed and wild animals) and can be transmitted to humans exposed to infected animals or infected products of animal origin (farmers, vets, butchers, carders, workers in the textile industry, etc.) [7]. The etiological agent of anthrax is Bacillus anthracis, a Gram-positive rod-shaped bacterium able to produce extremely resistant spores that, under unfavorable environmental conditions, can survive in the environment for several decades.

In particularly receptive animals (cattle, buffalo, sheep, goats, deer, and other wild ungulates), anthrax develops without apparent symptoms but has a fatal outcome characterized by sudden death due to acute or hyperacute septicemia and leakage of uncoagulated blood from natural openings.

In humans, anthrax can occur in three different forms with clinical signs dependent on the penetration route of the pathogen: cutaneous (generally non-fatal), pulmonary, and gastrointestinal [7]. Moreover, another fatal form has been described in drug users occurring after the intravenous injection of drugs contaminated with anthrax spores [2].

B. anthracis lives most of its existence in the form of a spore in soil, until ideal conditions develop allowing it to enter the reproductive cycle, which is presented mainly in domestic and wild ruminants. In animals, B. anthracis expresses its

Received 20 Aug. 2018, Revised 10 Nov. 2018, Accepted 30 Nov. 2018

*Corresponding author: Tel: +39-0881786330; Fax: +39-0881786205; E-mail: viviana.manzulli@izspb.it

This study was presented in part at the 16th Medical Biodefense Conference; October 28-31, 2018; Munich, Germany. 
pathogenic activity primarily through the antiphagocytic activity of the capsule (whose genes are localized on the pXO2 plasmid) and the production of a toxic complex consisting of three proteins: protective antigen (PA), lethal factor (LF), and edema factor (EF) (whose genes are localized on the $\mathrm{pXO} 1$ plasmid) [7].

In Italy, animal anthrax is an endemic disease and most of the recorded animal outbreaks are characterized as sporadic episodes occurring usually during summer and after a rainy spring. The occurrence of new cases is generally linked to climate changes (with major incidences under warmer and extreme weather) or human activities that interfere with soil surfaces (drainage- or excavation-related work). Cases typically involve a low number of animals (one to three on average) grazing on contaminated pastures. With the exception of rare outbreaks, the disease is predominantly diffused in southern and island regions of Italy, especially in Basilicata, Apulia, and Sicily [9]. In Italy, over the last 50 years, about 200 outbreaks of animal anthrax have been recorded, while, more recently, between 2006 and 2017, 5 human cases of cutaneous anthrax occurred (unpublished data).

Furthermore, B. anthracis is considered one of the most important agents of bioterrorism. Because of its characteristics, it can be potentially misused as a biological weapon, as was confirmed by bioterrorism events in the United States in 2001 [10]. Due to the often-fatal outcome of human cases, quick administration of definitely effective antimicrobials is crucial either in prophylaxis, after presumptive exposure, or for therapy of clinical cases.

\section{Materials and Methods}

\section{B. anthracis strains}

The $B$. anthracis strains selected for this study are members of the strain collection of the Anthrax Reference Institute of Italy (Ce.R.N.A.) located at the Istituto Zooprofilattico Sperimentale della Puglia e della Basilicata. The selected strains were isolated in Italy between 1984 and 2017 from different outbreaks and various sources: 2 strains were isolated from two different cases of human cutaneous anthrax, 102 were isolated from animals (50 from cattle, 34 from sheep, 10 from goats, 5 from horses, 1 from donkey, 1 from deer, and 1 from a pig), and 6 were isolated from environmental samples ( 1 from water and 5 from soils) (Table 1). In addition, $3 \mathrm{~B}$. anthracis vaccine strains were included: B. anthracis Sterne 34F2 (pXO1 ${ }^{+}, \mathrm{pXO} 2^{-}$), Carbosap $\left(\mathrm{pXO1}^{+}, \mathrm{pXO} 2^{+}\right)$, and Pasteur I type $\left(\mathrm{pXO1}^{-}, \mathrm{pXO} 2^{+}\right)$.

All strains have been identified and characterized to assess the presence of plasmids $\mathrm{pXO} 1$ and $\mathrm{pXO} 2$ by polymerase chain reaction (PCR) as previously described [8]. Moreover, all strains were genotyped by 15-loci multiple-locus variablenumber of tandem repeats analysis (MLVA) as reported by Van Ert et al. [13]. All work involving live B. anthracis was
Table 1. Characteristics and genotypes of the Bacillus anthracis strains tested in this study

\begin{tabular}{|c|c|c|c|c|c|}
\hline Isolate & Year & Source & pXO1 & $\mathrm{pXO} 2$ & MLVA 15 genotype \\
\hline 1 & 1984 & Sheep & + & + & 25 \\
\hline 2 & 1984 & Sheep & + & + & 1 \\
\hline 3 & 1984 & Sheep & + & + & 11 \\
\hline 4 & 1984 & Sheep & + & + & 2 \\
\hline 5 & 1984 & Sheep & + & + & 4 \\
\hline 6 & 1984 & Sheep & + & + & 1 \\
\hline 7 & 1984 & Sheep & + & + & 27 \\
\hline 8 & 1984 & Cattle & + & + & 27 \\
\hline 9 & 1984 & Cattle & + & + & 28 \\
\hline 10 & 1984 & Horse & - & + & 8 \\
\hline 11 & 1993 & Sheep & - & + & 21 \\
\hline 12 & 1993 & Sheep & + & + & 23 \\
\hline 13 & 1993 & Goat & - & + & 8 \\
\hline 14 & 1993 & Sheep & + & + & 10 \\
\hline 15 & 1993 & Sheep & + & + & 21 \\
\hline 16 & 1995 & Sheep & + & + & 27 \\
\hline 17 & 1995 & Cattle & + & + & 29 \\
\hline 18 & 1996 & Donkey & + & + & 2 \\
\hline 19 & 1996 & Goat & + & + & 16 \\
\hline 20 & 1997 & Cattle & + & + & 18 \\
\hline 21 & 1997 & Sheep & + & + & 20 \\
\hline 22 & 1997 & Sheep & + & + & 20 \\
\hline 23 & 1997 & Goat & + & + & 16 \\
\hline 24 & 1998 & Goat & + & + & 21 \\
\hline 25 & 1999 & Cattle & + & + & 10 \\
\hline 26 & 1999 & Cattle & + & + & 24 \\
\hline 27 & 1999 & Human & + & + & 2 \\
\hline 28 & 1999 & Sheep & + & + & 13 \\
\hline 29 & 1999 & Cattle & + & + & 5 \\
\hline 30 & 2000 & Sheep & + & + & 21 \\
\hline 31 & 2000 & Sheep & + & + & 7 \\
\hline 32 & 2000 & Cattle & + & + & 22 \\
\hline 33 & 2001 & Sheep & - & + & 12 \\
\hline 34 & 2001 & Cattle & + & + & 21 \\
\hline 35 & 2001 & Sheep & + & + & 1 \\
\hline 36 & 2002 & Cattle & + & + & 11 \\
\hline 37 & 2002 & Sheep & + & + & 2 \\
\hline 38 & 2002 & Sheep & + & + & 21 \\
\hline 39 & 2002 & Goat & + & + & 21 \\
\hline 40 & 2002 & Cattle & - & + & 2 \\
\hline 41 & 2002 & Cattle & + & + & 2 \\
\hline 42 & 2004 & Cattle & + & + & 15 \\
\hline 43 & 2004 & Horse & + & + & 1 \\
\hline 44 & 2004 & Deer & + & + & 1 \\
\hline 45 & 2004 & Goat & + & + & 1 \\
\hline 46 & 2004 & Cattle & + & + & 1 \\
\hline 47 & 2004 & Sheep & + & + & 1 \\
\hline 48 & 2004 & Goat & + & + & 1 \\
\hline 49 & 2004 & Goat & + & + & 1 \\
\hline
\end{tabular}


Table 1. Continued

\begin{tabular}{|c|c|c|c|c|c|}
\hline Isolate & Year & Source & $\mathrm{pXO1}$ & $\mathrm{pXO} 2$ & MLVA 15 genotype \\
\hline 50 & 2004 & Pigs & + & + & 1 \\
\hline 51 & 2005 & Goat & + & + & 21 \\
\hline 52 & 2005 & Cattle & + & + & 19 \\
\hline 53 & 2005 & Cattle & + & + & 19 \\
\hline 54 & 2005 & Cattle & + & + & 19 \\
\hline 55 & 2005 & Cattle & + & + & 19 \\
\hline 56 & 2006 & Sheep & + & + & 4 \\
\hline 57 & 2006 & Soil & + & + & 1 \\
\hline 58 & 2006 & Cattle & + & + & 1 \\
\hline 59 & 2006 & Cattle & + & + & 2 \\
\hline 60 & 2007 & Cattle & + & + & 30 \\
\hline 61 & 2008 & Sheep & + & + & 21 \\
\hline 62 & 2008 & Cattle & + & + & 2 \\
\hline 63 & 2008 & Water & + & + & 2 \\
\hline 64 & 2008 & Soil & + & + & 2 \\
\hline 65 & 2009 & Cattle & + & + & 3 \\
\hline 66 & 2009 & Soil & + & + & 10 \\
\hline 67 & 2009 & Cattle & + & + & 17 \\
\hline 68 & 2009 & Sheep & + & + & 21 \\
\hline 69 & 2009 & Cattle & + & + & 17 \\
\hline 70 & 2009 & Cattle & + & + & 17 \\
\hline 71 & 2009 & Cattle & + & + & 17 \\
\hline 72 & 2009 & Cattle & + & + & 17 \\
\hline 73 & 2009 & Sheep & + & + & 1 \\
\hline 74 & 2009 & Cattle & + & + & 1 \\
\hline 75 & 2011 & Sheep & + & + & 21 \\
\hline 76 & 2011 & Cattle & + & + & 6 \\
\hline 77 & 2011 & Horse & + & + & 21 \\
\hline 78 & 2011 & Horse & + & + & 6 \\
\hline 79 & 2011 & Cattle & + & + & 6 \\
\hline 80 & 2011 & Sheep & + & + & 6 \\
\hline 81 & 2011 & Cattle & + & + & 6 \\
\hline 82 & 2011 & Cattle & + & + & 21 \\
\hline 83 & 2011 & Horse & + & + & 21 \\
\hline 84 & 2011 & Sheep & + & + & 21 \\
\hline 85 & 2011 & Sheep & + & + & 21 \\
\hline 86 & 2012 & Cattle & + & + & 17 \\
\hline 87 & 2012 & Cattle & + & + & 17 \\
\hline 88 & 2012 & Cattle & + & + & 17 \\
\hline 89 & 2012 & Human & + & + & 26 \\
\hline 90 & 2012 & Soil & + & + & 1 \\
\hline 91 & 2012 & Cattle & + & + & 2 \\
\hline 92 & 2012 & Cattle & + & + & 2 \\
\hline 93 & 2012 & Cattle & + & + & 2 \\
\hline 94 & 2012 & Cattle & + & + & 2 \\
\hline 95 & 2013 & Soil & + & + & 1 \\
\hline 96 & 2014 & Cattle & + & + & 1 \\
\hline 97 & 2014 & Cattle & + & + & 6 \\
\hline 98 & 2014 & Cattle & + & + & 18 \\
\hline 99 & 2016 & Sheep & + & + & 21 \\
\hline
\end{tabular}

Table 1. Continued

\begin{tabular}{cccccc}
\hline Isolate & Year & Source & pXO1 & pXO2 & MLVA \\
\hline 100 & 2016 & Goat & + & + & 1 \\
101 & 2016 & Sheep & + & + & 4 \\
102 & 2016 & Sheep & + & + & 4 \\
103 & 2016 & Sheep & + & + & 4 \\
104 & 2016 & Cattle & + & + & 19 \\
105 & 2016 & Cattle & + & + & 19 \\
106 & 2016 & Cattle & + & + & 19 \\
107 & 2017 & Cattle & + & + & 15 \\
108 & 2017 & Cattle & + & + & 15 \\
109 & 2017 & Cattle & + & + & 15 \\
110 & 2017 & Cattle & + & + & 15 \\
\hline
\end{tabular}

MLVA, multiple-locus variable-number of tandem repeats analysis.

performed in a biosafety level 3 laboratory within a class II safety cabinet.

\section{Antimicrobial susceptibility testing}

Antimicrobial susceptibility was determined by applying a broth microdilution method according to Clinical and Laboratory Standards Institute (CLSI) guidelines [4,5]. The following most-common broad-spectrum antimicrobials, all from Acros Organics (Thermo Fisher Scientific, USA), were used at the indicated concentrations: gentamicin (0.008-16 $\mu \mathrm{g} / \mathrm{mL})$, streptomycin $(0.015-32 \mu \mathrm{g} / \mathrm{mL})$, penicillin $\mathrm{G}(0.001-2$ $\mu \mathrm{g} / \mathrm{mL})$, amoxicillin $(0.008-16 \mu \mathrm{g} / \mathrm{mL})$, clindamycin $\left(0.008^{-}\right.$ $16 \mu \mathrm{g} / \mathrm{mL})$, chloramphenicol $\left(0.06^{-128} \mu \mathrm{g} / \mathrm{mL}\right)$, vancomycin $(0.06-64 \mu \mathrm{g} / \mathrm{mL})$, linezolid $(0.06-64 \mu \mathrm{g} / \mathrm{mL})$, erythromycin $(0.008-16 \mu \mathrm{g} / \mathrm{mL})$, tetracycline $(0.008-16 \mu \mathrm{g} / \mathrm{mL})$, ciprofloxacin (0.004-8 $\mu \mathrm{g} / \mathrm{mL})$, doxycycline $(0.004-4 \mu \mathrm{g} / \mathrm{mL})$, rifampin $(0.004-8 \mu \mathrm{g} / \mathrm{mL})$, cefotaxime $(0.25-512 \mu \mathrm{g} / \mathrm{mL})$, ceftriaxone $(0.25-512 \mu \mathrm{g} / \mathrm{mL})$, and trimethoprim $(0.125-128 \mu \mathrm{g} / \mathrm{mL})$. Each molecule was dissolved in the appropriate solvent and two-fold diluted in cation-adjusted Mueller Hinton broth (CAMHB) (BD Biosciences, USA) using microplates (100 $\mu \mathrm{L} /$ well).

Overnight cultures of each $B$. anthracis strain were suspended in sterile saline to match a $0.5 \mathrm{McFarland}$ standard using a densitometer. The cell suspensions were further diluted 1:100 in CAMHB to obtain a bacterial concentration of approximately $1-5 \times 10^{4} \mathrm{CFU} / \mathrm{mL}$ (CFU, colony-forming unit), and $100 \mu \mathrm{L}$ bacterial aliquots were added to each well of the microplate.

Two microliters of a resazurin solution $(6.75 \mathrm{mg} / \mathrm{mL})$ (Sigma-Aldrich, USA) were added to each well to assess bacterial growth [11], and the plates were incubated overnight at $37^{\circ} \mathrm{C}$. The color change caused by the resazurin was observed in the plate wells: a change from purple to pink/colorless indicated cell growth. The lowest concentration of each antibiotic that prevented bacterial growth was deemed the 
minimal inhibitory concentration (MIC). The use of resazurin allowed easy detection of microbial growth in extremely small solution volumes in microtiter plates; thus, there was no need for spectrophotometry of the plate samples.

The reported CLSI breakpoints $(\mu \mathrm{g} / \mathrm{mL})$ for $B$. anthracis were used for penicillin, amoxicillin, ciprofloxacin, doxycycline, and tetracycline while the breakpoints for Bacillus spp. were used for the cephem antibiotics [4]. Interpretative criteria for Staphylococcus spp. were used for gentamicin, clindamycin, chloramphenicol, vancomycin, linezolid, erythromycin, rifampin, and trimethoprim, according to CLSI guidelines [5]. As CLSI breakpoints for streptomycin were not available, it was not possible to give any comparable interpretation to the activity of this antimicrobial.

To check the validity of the antimicrobial susceptibility testing method, Staphylococcus aureus ATCC 29213 and Escherichia coli ATCC 25922 were tested in parallel as control strains.

\section{Results}

The $B$. anthracis pX01 plasmid was not detected by PCR in five of the examined strains, including the Pasteur I type vaccine strain, whereas the $\mathrm{pX} 02$ plasmid of $B$. anthracis was present in all examined strains except the Sterne vaccine strain (Table 1). In total, 30 different genotypes were identified by the 15-loci MLVA (Table 1), and to each genotype, an identification number was arbitrarily attributed by Ce.R.N.A. (data not shown). The concentration that inhibited the growth of $50 \%$ $\left(\mathrm{MIC}_{50}\right)$ and $90 \%\left(\mathrm{MIC}_{90}\right)$ of the isolates, the MIC range of each antimicrobial substance tested, and the susceptibility percentages are shown in Table 2.

\section{Discussion}

Antimicrobial susceptibility testing has a key role in the management of anthrax infections. In this study, a total of $110 \mathrm{~B}$. anthracis strains, isolated in Italy between 1984 and 2017 were studied to determine their susceptibility to antimicrobials. The presence of virulence factors, which were evaluated by PCR, showed that all isolates, except the Sterne vaccine strain, harbored the capC gene (on plasmid pXO2). The pagA, lef, and cya genes (on plasmid pXO1 and encoding PA, LF, and EF, respectively) were not detected in five of the tested isolates. However, it appeared that the susceptibility to antimicrobials of isolates lacking plasmids was comparable to those with both pXO1 and pXO2 plasmids.

All isolates were susceptible to most of the tested antimicrobial with the exception of trimethoprim, as expected [1], for which a high level of resistance was observed, whereas for ceftriaxone and cefotaxime intermediate susceptibility levels were recorded. The results are in agreement with other previously published studies [6]. Moreover, all 30 investigated genotypes showed no difference in antimicrobial susceptibility,

Table 2. Antibiotic susceptibilities of 110 Bacillus anthracis strains isolated during anthrax outbreaks in Italy

\begin{tabular}{|c|c|c|c|c|c|c|c|c|c|}
\hline \multirow{2}{*}{ Antimicrobial agent } & \multicolumn{3}{|c|}{$\mathrm{MIC}(\mu \mathrm{g} / \mathrm{mL})$} & \multicolumn{3}{|c|}{ MIC breakpoints ( $\mu \mathrm{g} / \mathrm{mL})$} & \multicolumn{3}{|c|}{$\begin{array}{l}\text { Percent of isolates with the } \\
\text { following interpretation }\end{array}$} \\
\hline & Range & $50 \% *$ & $90 \% *$ & $\mathrm{~S}(\leq)$ & I & $\mathrm{R}(\geq)$ & $\mathrm{S}$ & I & $\mathrm{R}$ \\
\hline Gentamicin & $0.008-16$ & 0.125 & 0.25 & 4 & 8 & 16 & 100 & - & - \\
\hline Streptomycin & $0.015^{-32}$ & 0.5 & 1 & - & - & - & - & - & - \\
\hline Penicillin G & $0.001-2$ & 0.015 & 0.03 & 0.5 & - & 1 & 100 & - & - \\
\hline Amoxicillin & $0.008-16$ & 0.06 & 0.06 & 0.12 & - & 0.25 & 100 & - & - \\
\hline Clindamycin & $0.008-16$ & 0.125 & 0.25 & 0.5 & $1-2$ & 4 & 100 & - & - \\
\hline Chloramphenicol & $0.06-128$ & 4 & 4 & 8 & 16 & 32 & 100 & - & - \\
\hline Vancomycin & $0.06-64$ & 2 & 2 & 2 & $4-8$ & 16 & 100 & - & - \\
\hline Linezolid & $0.06-64$ & 1 & 2 & 4 & - & 8 & 100 & - & - \\
\hline Erythromycin & $0.008-16$ & 0.125 & 0.25 & 0.5 & $1-4$ & 8 & 100 & - & - \\
\hline Tetracycline & $0.008-16$ & 0.06 & 0.125 & 1 & - & - & 100 & - & - \\
\hline Ciprofloxacin & $0.004-8$ & 0.03 & 0.03 & 0.25 & - & - & 100 & - & - \\
\hline Doxycycline & $0.004-4$ & 0.015 & 0.03 & 1 & - & - & 100 & - & - \\
\hline Rifampin & $0.004-8$ & 0.125 & 0.25 & 1 & 2 & 4 & 100 & - & - \\
\hline Ceftriaxone & $0.25-512$ & 16 & 16 & 8 & $16-32$ & 64 & - & 100 & - \\
\hline Cefotaxime & $0.25-512$ & 16 & 16 & 8 & $16-32$ & 64 & - & 100 & - \\
\hline Trimethoprim & $0.125-128$ & $>128$ & $>128$ & 8 & - & 16 & - & - & 100 \\
\hline
\end{tabular}

MIC, minimal inhibitory concentration; S, susceptible; I, intermediate; R, resistant. ${ }^{*} \mathrm{MIC}$ at which $50 \%$ or $90 \%$ of tested isolates are inhibited. 
probably due to the high genetic homogeneity of $B$. anthracis.

There are few reports on the antimicrobial susceptibility profiles of $B$. anthracis. This can be probably explained by the rarity of human anthrax in industrialized and developed countries, where the most of the scientific research is concentrated, by the elaboration of effective control programs over the last 50 years and by efficient therapies with wellknown antimicrobials such as amoxicillin, doxycycline, ciprofloxacin, and penicillin [3,12]. The latter are the antibiotics of first choice, as recommended by the Centers for Disease Control and Prevention, for the treatment of anthrax in human cases.

In order to be effective, an antimicrobial treatment should be timely, starting immediately after infection. Healing is possible if you intervene in the initial stages of the disease, and the late administration of antibiotics is often useless. The results in the present study suggest a high degree of in vitro susceptibility of B. anthracis to many antimicrobials. The effective activity of gentamicin, streptomycin, clindamycin, chloramphenicol, vancomycin, linezolid, tetracycline, erythromycin, and rifampin, on all tested $B$. anthracis strains demonstrates several appropriate alternative antimicrobials for $B$. anthracis prophylaxis and/or treatment. All of the tested $B$. anthracis strains showed intermediate susceptibility to cephems (cefotaxime and ceftriaxone) and resistance to trimethoprim. The resistance of $B$. anthracis to trimethoprim supports a previous report of an intrinsic resistance of $B$. anthracis to this compound [1].

The relationship between the indications obtainable from in vitro tests and the real clinical efficacy of an antimicrobial is obviously not absolute and depends on a complex set of factors including the effective in vivo role of the microorganism and the correct modality and timing of administration of the antimicrobial, as well as the pharmacokinetic and pharmacodynamic characteristics of the antimicrobial.

Interestingly, in this study, we demonstrated that the $B$. anthracis isolates, belonging to different genotypes and isolated from different sources over a long period (1984-2017) showed the same levels of susceptibility to the tested antimicrobials. Further monitoring of the antibiotic susceptibility of $B$. anthracis is important for the identification of resistant clones and for choosing the best therapeutic strategy when an anthrax outbreak occurs.

\section{Acknowledgments}

The authors would like to thank Michela Iatarola, Angela Aceti, Elena Poppa and Francesco Tolve for the skillful technical support. This study was funded by the Ministry of Health of Italy, Current Research 2017, project "IZSPB 03/17", which supported the work of Istituto Zooprofilattico Sperimentale della Puglia e della Basilicata. The funders had no role in study design, data collection, and interpretation, or the decision to submit the work for publication.

\section{Conflict of Interest}

The authors declare no conflicts of interest.

\section{References}

1. Barrow EW, Boume PC, Barrow WW. Functional cloning of Bacillus anthracis dihydrofolate reductase and confirmation of natural resistance to trimethoprim. Antimicrob Agents Chemother 2004, 48, 4643-4649.

2. Berger T, Kassirer M, Aran AA. Injectional anthrax - new presentation of an old disease. Euro Surveill 2014, 19, 20877.

3. Cavallo JD, Ramisse F, Giradet M, Vaissaire J, Mock M, Hemandez E. Antibiotic susceptibilities of 96 isolates of Bacillus anthracis isolated in France between 1994 and 2000. Antimicrob Agents Chemother 2002, 46, 2307-2309.

4. Clinical and Laboratory Standards Institute (CLSI). Methods for Antimicrobial Dilution and Disk Susceptibility Testing of Infrequently Isolated or Fastidious Bacteria. 3rd ed. CLSI Guideline M45. CLSI, Wayne, 2016.

5. Clinical and Laboratory Standards Institute (CLSI). Performance Standards for Antimicrobial Susceptibility Testing. 27th ed. CLSI Supplement M100. CLSI, Wayne, 2017.

6. Esel D, Doganay M, Sumerkan B. Antimicrobial susceptibilities of 40 isolates of Bacillus anthracis isolated in Turkey. Int J Antimicrob Agents 2003, 22, 70-72.

7. Fasanella A, Galante D, Garofolo G, Jones MH. Anthrax undervalued zoonosis. Vet Microbiol 2010, 140, 318-331.

8. Fasanella A, Losito S, Trotta T, Adone R, Massa S, Ciuchini F, Chiocco D. Detection of anthrax vaccine virulence factors by polymerase chain reaction. Vaccine 2001, 19, 4214-4218.

9. Fasanella A, Van Ert M, Altamura SA, Garofolo G, Buonavoglia C, Leori G, Huynh L, Zanecki S, Keim P. Molecular diversity of Bacillus anthracis in Italy. J Clin Microbiol 2005, 43, 3398-3401.

10. Hudson MJ, Beyer W, Böhm R, Fasanella A, Garofolo G, Golinski R, Goossens PL, Hahn U, Hallis B, King A, Mock M, Montecucco C, Ozin A, Tonello F, Kaufmann SH. Bacillus anthracis: balancing innocent research with dual-use potential. Int J Med Microbiol 2008, 298, 345-364.

11. Sarker SD, Nahar L, Kumarasamy Y. Microtitre plate-based antibacterial assay incorporating resazurin as an indicator of cell growth, and its application in the in vitro antibacterial screening of phytochemicals. Methods 2007, 42, 321-324.

12. Tumbull PC, Sirianni NM, LeBron CI, Samaan MN, Sutton FN, Reyes AE, Peruski LF Jr. MICs of selected antibiotics for Bacillus anthracis, Bacillus cereus, Bacillus thuringiensis, and Bacillus mycoides from a range of clinical and environmental sources as determined by the Etest. J Clin Microbiol 2004, 42, 3626-3634.

13. Van Ert MN, Easterday WR, Huynh LY, Okinaka RT, Hugh-Jones ME, Ravel J, Zanecki SR, Pearson T, Simonson TS, U'Ren JM, Kachur SM, Leadem-Dougherty RR, Rhoton SD, Zinser G, Farlow J, Coker PR, Smith KL, Wang B, Kenefic LJ, Fraser-Liggett CM, Wagner DM, Keim P. Global genetic population structure of Bacillus anthracis. PLoS One 2007, 2, e461. 